\title{
April 2017 Critical Care Case of the Month
}

\author{
Robert A. Raschke, MD \\ Banner University Medical Center-Phoenix \\ Phoenix, AZ USA
}

\section{History of Present IIIness}

A 20-year-old woman was transferred from another medical center for care. She was pregnant and initially presented with a one day history of crampy abdominal pain with nausea and vomiting after eating old, bad tasting chicken two days previously. She had pain of her right arm and a non-displaced humeral fracture was seen on $x$-ray. The etiology of the fracture was unclear. Her illness rapidly progressed to respiratory distress requiring intubation. The fetus had deceleration of heart tones leading to a cesarean section and delivery of a nonviable infant. Subsequently, she had rapid progression of shock and anuria.

\section{Past Medical History}

She had a previous history of a seizure disorder which was managed with levetiracetam, clonazepam, and folic acid. There was a previous intentional opiate overdose 2 years earlier. One month prior to admission she had visited her husband in Iraq. After returning to the US 3 weeks prior to admission, she developed a sore throat and was treated with penicillin. She smokes tobacco hookah and marijuana. There is a positive family history of gout.

\section{Physical Examination}

- Vital signs: heart rate 109, blood pressure 102/78 mm Hg while on norepinephrine, respiratory rate 22 , temperature $36.5^{\circ} \mathrm{C}$.

- General: She was sedated and intubated. She had a splint on her right arm.

- Lungs: clear anteriorly

- Heart: regular rhythm without murmur

- Abdomen: firm without palpable organomegaly or masses.

- Neurological examination: There was movement of all extremities. Muscle tone was normal. Deep tendon reflexes were normal. Plantar reflexes were down going.

- Skin: diffuse erythematous macular popular rash on the trunk and back (Figure 1). 


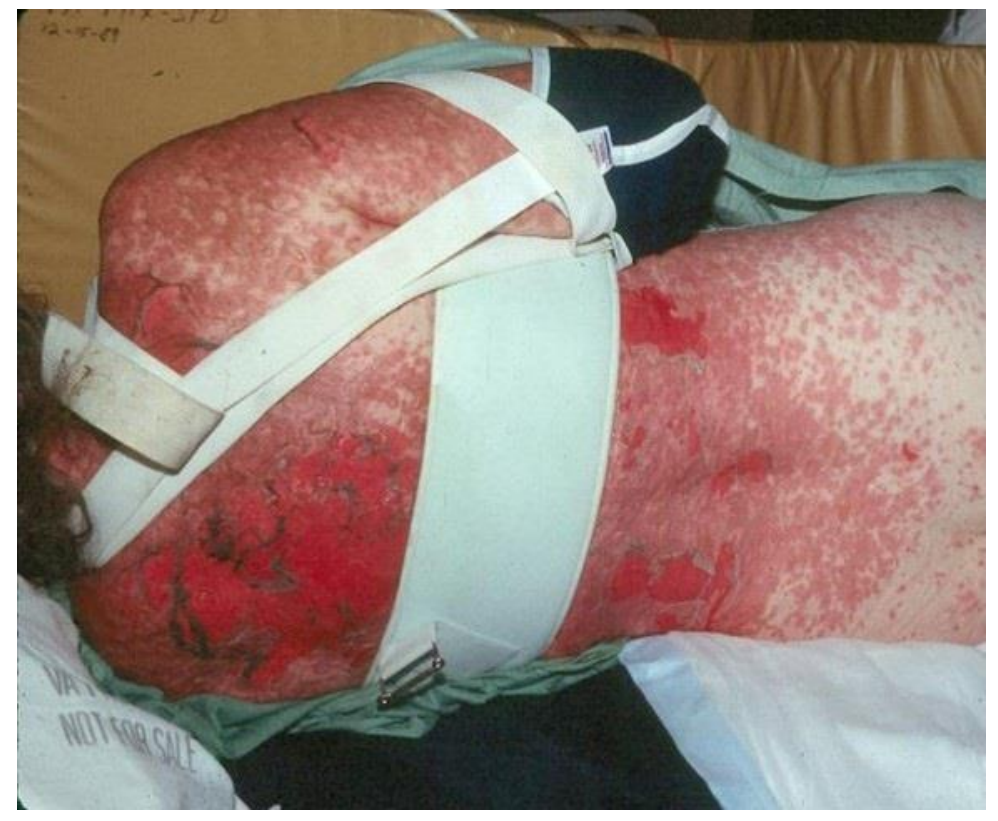

Figure 1. Photograph of patient's back showing rash.

\section{Initial Laboratory Evaluation}

CBC: hemoglobin $14.5 \mathrm{gm} / \mathrm{dL}$, platelet count 299,000 cells/mcL, WBC 41,000 cells/mcL, vacuolated polymorphonuclear leukocytes were noted Electrolytes: $\mathrm{Na}^{+} 135 \mathrm{mmol} / \mathrm{L}, \mathrm{K}^{+} 4.9 \mathrm{mmol} / \mathrm{L}, \mathrm{Cl}^{-} 95 \mathrm{mmol} / \mathrm{L}, \mathrm{HCO}^{-} 18 \mathrm{mmol} / \mathrm{L}$ Renal function: creatinine $3.9 \mathrm{mg} / \mathrm{dL}$, blood urea nitrogen (BUN) $59 \mathrm{mg} / \mathrm{dL}$ Liver enzymes: AST 294 (normal 8-48 U/L), ALT 303 (normal 7-55 U/L), ALP 187 (normal 45-115 U/L).

Glucose: 58

Which of the following should be done immediately?

1. Bedside echocardiography

2. Liver biopsy

3. Urine drug screen

4. 1 and 3

5. All of the above 


\section{Correct!}

\section{1 and 3}

The patient is hypotensive and beside echocardiography has been shown to be helpful in patient management (1). The patient's ejection fraction was estimated to be $30 \%$ with global hypokinesis. Inferior vena cava size was $2.6 \mathrm{~cm}$. Urine drug screen was positive only for benzodiazepines. She had been receiving midazolam for sedation and as an anticonvulsant. Although liver enzymes are abnormal, liver biopsy at this juncture is risky and not indicated.

Additional laboratory that was obtained included blood cultures, N-terminal probrain naturetic peptide 18,615 (normal $<300 \mathrm{pg} / \mathrm{mL}$ ), and lactate was elevated at 3.8 (normal $<2 \mathrm{mmol} / \mathrm{L}$ ).

Which of the following are indicated based on the initial laboratory evaluation?

1. Broad spectrum antibiotics

2. Intravenous glucose

3. Stress dose corticosteroids

4. 1 and 3

5. All of the above 


\section{Correct! \\ 5. All of the above}

An explanation for her overall clinical picture is not clear. Certainly, she could be septic and broad spectrum antibiotics while awaiting culture results is reasonable. Hypoglycemia has been associated with increased mortality and glucose infusion to maintain a glucose is indicated. She is hypotensive from apparent cardiogenic shock but adrenal insufficiency is common in ICU patient and stress dose corticosteroids while awaiting cortisol levels is reasonable.

Blood cultures, sputum and urine cultures were all negative for pathogens. Cortisol levels were normal. Three days after transfer she developed pancytopenia with a white blood cell count dropping below 1000 cells $/ \mathrm{mcL}$. She was undergoing daily or every other day dialysis because of her renal failure and anuria.

Which of the following are possible explanations of her overall clinical picture?

1. DRESS syndrome

2. Hemophagocytic lymphohistiocytosis

3. Sepsis

4. 1 and 3

5. All of the above 


\section{Correct! \\ 5. All of the above}

All would seem possible. Culture negative sepsis is common and quite possible. although cultures remained negative, the patient was on multiple antibiotics.

Hemophagocytic lymphohistiocytosis or HLH is disease of severe hyperinflammation caused by uncontrolled proliferation of activated lymphocytes and macrophages (2). Fulfillment of five out of the eight criteria listed below is considered presumptive evidence for HLH:

- Fever

- Splenomegaly

- Cytopenias (affecting at least two of three lineages in the peripheral blood):

- Pancytopenia

- Hypertriglyceridemia (fasting, greater than or equal to $265 \mathrm{mg} / 100 \mathrm{ml}$ ) and/or hypofibrinogenemia (less than or equal to $150 \mathrm{mg} / 100 \mathrm{ml}$ )

- Hemophagocytosis in bone marrow, spleen or lymph nodes

- Low or absent NK cell activity

- Ferritin greater than or equal to $500 \mathrm{ng} / \mathrm{ml}$

- Soluble CD25 (that is, soluble IL-2 receptor) $>2400 \mathrm{U} / \mathrm{ml}$ (or per local reference laboratory)

Our patient met many of these criteria with an elevated ferritin level (5190 $\mathrm{ng} / \mathrm{mL}$ ), hypertriglyceridemia (1158 mg/dL) and soluble $\mathrm{IL}-2 \mathrm{R}>2500 \mathrm{U} / \mathrm{ml}$. However, bone marrow aspiration and biopsy did not show hemophagocytosis or histiocytosis.

Drug Reaction with Eosinophila and Systemic Symptoms, or DRESS syndrome, is used to describe patients exhibiting a drug-induced condition characterized by an extensive rash, fever, lymphadenopathy, hematologic abnormalities, hepatitis, and involvement of the kidneys, lungs, heart, or pancreas. More than 50 drugs have been linked to DRESS syndrome. The drugs most often reported with DRESS include anticonvulsants (particularly those with aromatic structures), sulfa derivatives, antidepressants, nonsteroidal anti-inflammatory drugs, and antimicrobials. The onset of symptoms is often delayed, occurring 2-6 weeks after drug initiation. DRESS syndrome shares many characteristics in common with anticonvulsant hypersensitivity syndrome (AHS), also referred to as druginduced hypersensitivity syndrome (DIHS), and appears to represent a variation in presentation rather than a distinctly different syndrome. One definition of DRESS is that patients must have three of the four criteria: an acute rash, fever above $38^{\circ} \mathrm{C}$, lymphadenopathy at two sites, involvement of at least one internal organ, and abnormalities in lymphocyte and eosinophil counts. Additional criteria include hospitalization and that the reaction is suspected to be drug-related. Our patient meant many of these criteria but pancytopenia is uncommon in DRESS syndrome. 
Because of the possibility of DRESS syndrome, a toxicology consult was obtained. Additional history from various members of the patient's family revealed that the patient was a Muslim-immigrant lesbian married to a cousin in Iraq in an arranged marriage. She had attempted suicide with an acetaminophen and oxycodone overdose when she broke up with her girlfriend.

Based on her clinical presentation, the toxicologist raised what additional possible drug toxicity?

1. Acetaminophen/hydrocodone

2. Colchicine

3. Lithium

4. Opiate overdose

5. Organic phosphate 


\section{Correct! \\ 2. Colchicine}

The patient's father took colchicine and the entire case began with her eating "bad tasting" chicken. Colchicine toxicity occurs in 3 stages (Table 2) (3).

Table 2. Phases of colchicine toxicity.

- Phase 1 (First 24 hours): nausea, vomiting, diarrhea, abdominal pain, leukocytosis.

- Phase 2 (1-7 days): Shock, multiple organ dysfunction syndrome, cardiomyopathy, pancytopenia, disseminated intravascular coagulation, rash.

- Phase 3 (> 1 week): recovery alopecia, rebound leukocytosis

Our patient's colchicine level was $7.2 \mathrm{ng} / \mathrm{ml}$ several days after presentation. Colchicine is a poison of the microtubules which are involved in a variety of cellular movements and cell division which explains its diffuse toxic effects.

Opiate toxicity results in respiratory depression. Acetaminophen/hydrocodone overdosage could result in respiratory depression from the hydrocodone and progressive liver toxicity from the acetaminophen. Organophosphate poisoning is usually associated with cholinergic syndrome. Neuromuscular signs such as tremulousness, dystonia, hyperreflexia, and ataxia are usually prominent in acute lithium toxicity.

Our patient was supported with granulocyte colony stimulating factor which was ineffective in raising the white blood cell count. She developed progressive shock, abdominal compartment syndrome, and her lactate rose to $16 \mathrm{mmol} / \mathrm{L}$. She died 9 days after transfer. The source of the colchicine poisoning remains unclear. It could have been self-induced or a homicide attempt.

\section{References}

1. Labovitz AJ, Noble VE, Bierig M, et al. Focused cardiac ultrasound in the emergent setting: a consensus statement of the American Society of Echocardiography and American College of Emergency Physicians. J Am Soc Echocardiogr. 2010 Dec;23(12):1225-30. [CrossRef] [PubMed]

2. Raschke RA, Garcia-Orr R. Hemophagocytic lymphohistiocytosis: a potentially underrecognized association with systemic inflammatory response syndrome, severe sepsis, and septic shock in adults. Chest. 2011 Oct;140(4):933-8. [CrossRef] [PubMed]

3. Buck ML. DRESS syndrome. Medscape. 2012. Available at: http://www.medscape.com/viewarticle/776164 1 (accessed 3/25/17).

4. Finkelstein $\mathrm{Y}, \mathrm{Aks} \mathrm{SE}$, Hutson JR, et al. Colchicine poisoning: the dark side of an ancient drug. Clin Toxicol (Phila). 2010 Jun;48(5):407-14. [CrossRef] [PubMed] 